\title{
Idosos em Experimentação no Circuito Urbano: Relato de uma Experiência
}

Seniors In Trial In The Urban Circuit: Report Of An Experience

Ancianos En Experimentación En El Circuito Urbano: Relato De Una Experiencia

Méri Vanessa Elias, Sidineia Aparecida Pizzeti \& Danielle Jardim Barreto

Universidade Paranaense

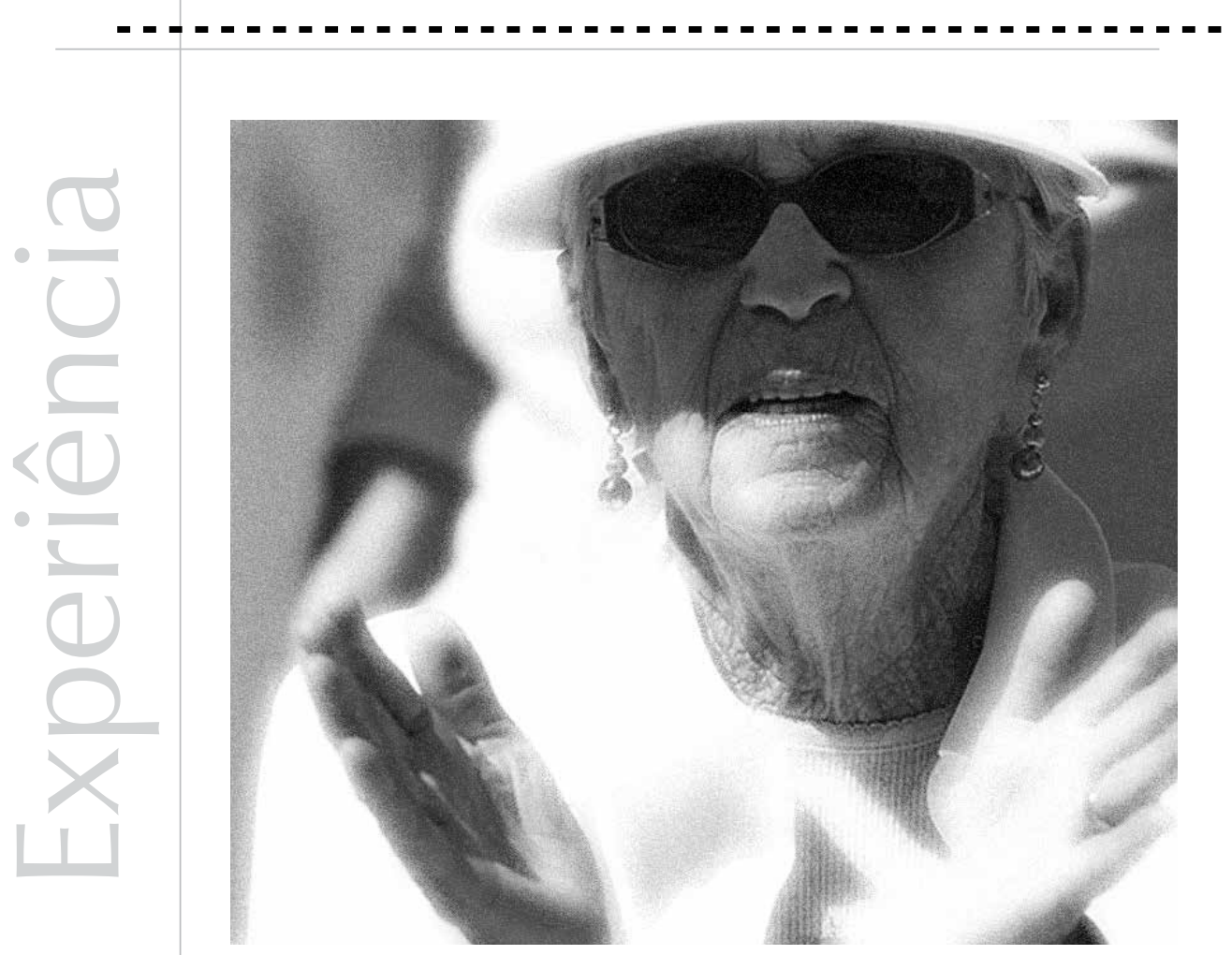


Resumo: Este artigo apresenta o relato de uma experiência realizada ao longo de dois anos com idosos frequentadores de um centro de convivência. A partir da inserção na instituição e da análise crítica acerca dos agenciamentos subjetivos engendrados no ambiente institucional, surgiu a necessidade de pensar sobre uma modalidade diferenciada de atendimento à demanda dessa população. Propôs-se a construção de um espaço de circulação por outros territórios bem como o encontrar-se em experimentações jamais imaginadas. Assim, tal anseio se materializou sob a forma de oficinas de passeios, realizadas por circuitos urbanos, visando-se a criar espaços de ressignificação. Os resultados atingidos mostraram que os idosos atendidos na oficina passaram a perceber que podem transcender o dado e experenciar, como sujeitos, o ato dos povos nômades: existir em um constante movimento de se desterritorializar e se reterritorializar, enfim, viver a humanidade naquilo que ela tem de singular: a possibilidade de, a cada novo dia, se reinventar.

Palavras-chave: Integração social. Modo de vida. Idosos. Qualidade de vida.

Abstracts: This article presents an account of a two year experiment conducted with the elderly who attended a community center. The need of thinking of a different way of care for this population came after they joined the institution and after a critical analysis about the engendered subjective assemblages in the institutional environment was made. The construction of a circulation space in other territories was proposed, as well as meetings in experimentations never imagined before. Thus, this longing materialized in the form of workshop rides, carried out in urban circuits, that aimed to create spaces for the reframing of old concepts. The results obtained showed that the elderly who attended the workshop came to realize that they can transcend what's given, and be the subjects of experiencing the act of nomadic peoples: exist in a constant movement of deterritorialization and reterritorialization, in other words, live their humanity in its singularity: the possibility of reinvent themselves each day.

Keywords: Social integration. Lifestyle. Seniors. Quality of life.

Resumen: Este artículo presenta un relato de una experiencia realizada a lo largo de dos años con ancianos frecuentadores de un centro de convivencia. A partir de la inserción en la institución y del análisis crítico acerca de los agenciamientos subjetivos engendrados en el ambiente institucional, surgió a la necesidad de pensar una modalidad diferenciada de atención a la demanda de esa población. Se propuso la construcción de un espacio de circulación por otros territorios, así como el encontrarse en experimentaciones jamás imaginadas. Así, tal ansia se materializó bajo la forma de "oficinas de paseos", realizadas por circuitos urbanos, con la intención de crear espacios de resignificación. Los resultados alcanzados mostraron que los ancianos atendidos en la oficina pasaron a percibir que pueden transcender lo dado, y de experimentar como sujeto el acto de los pueblos nómades: existir en un constante movimiento de desterritorializarse y se reterritorializar. En fin, vivir la humanidad en aquello que esta tiene de singular: la posibilidad de, cada nuevo día, reinventarse.

Palabras clave: Integración social. Circuitos urbanos. Ancianos. Calidad de vida.

Este trabalho constitui-se de considerações provenientes de atividades de Estágio Supervisionado Curricular Obrigatório Básico (ESCO), realizado durante dois anos, em um centro de convivência de cunho público localizado em uma cidade no interior do Paraná. A proposta de intervenção organizou-se a partir de nosso transitar no território institucional e, principalmente, nas afetações produzidas durante esse percurso.

$\mathrm{Na}$ instituição, percebemos uma forma de estar no mundo peculiar no que concerne o envelhecer como nos é proposto na contemporaneidade, pois os utentes apresentavam, em seus relatos, a conformação com a ideia de envelhecimento como sinônimo de fim de linha. É como se, de forma análoga, nos deparássemos com trens à beira de precipícios, para os quais a única possibilidade existente fosse o abismo. Notamos que a participação nas atividades propostas no centro de convivência nem sempre era autônoma, parecendo haver certa cobrança de obrigatoriedade por parte dos agentes institucionais.

Maia, Castro e Jordão (2010) comungam dessas acepções ao pontuarem, em um relato de experiência realizado em um asilo, que os primeiros contatos com os usuários dos serviços prestados pela instituição geraram um sentimento de estranhamento, posto 
Na cultura brasileira, o corpo é compreendido como um capital

(Goldenberg, 2011). que os velhos apresentavam-se apáticos, e que, na maioria das situações, recusavamse a realizar as atividades que lhes eram propostas.

Sublinha-se que os idosos que estavam no local em que estagiamos traziam, em seus discursos, conteúdos que delatavam o seu sentimento de não pertencimento ao circuito urbano, parecendo que o seu circular resumia-se a: casa - instituição, ou seja, que a cidade não se apresentava como um território de livre acesso.

Naculturabrasileira, ocorpoécompreendido como um capital (Goldenberg, 2011). Diante dessa compreensão, ao pensar-se em valores, poderíamos indagar: $\mathrm{O}$ quanto vale um corpo velho? Teria o valor que $\mathrm{o}$ permitiria trafegar por outras vias? Ao velho seria possível circular por outros territórios e esbarrar em outros corpos?

Pensa-se que tais questionamentos possam estar presentes no imaginário de nossos sujeitos, e possivelmente limitando os encontros que lhes são possíveis. Nesse âmbito, é importante citar duas constatações que nos são diariamente apresentadas: a primeira é que a população idosa do País tende a aumentar gradativamente, o que é corroborado por Morais (2009) ao ressaltar que o Brasil se tornará um país de velhos. Sobressaem-se dois fatores como determinantes nesse processo: diminuição da natalidade, uma vez que o mercado dispõe de diversos métodos contraceptivos, e diminuição da mortalidade, tendo em vista que os avanços tecnológicos e científicos proporcionam o aumento da expectativa de vida, sendo que o segundo fator é representado pela incansável luta humana e científica pela busca da imortalidade.

Os resquícios dessa luta são observados nos noticiários quando nos são apresentados sujeitos que são viciados na imagem, a tal ponto que se submetem a inúmeros procedimentos cirúrgicos objetivando conquistar o corpo perfeito (Morais, 2009). Goldenberg colabora ao aferir que as mulheres brasileiras ocupam o segundo lugar no pódio, perdendo apenas para as norteamericanas no quesito consumo de cirurgia plástica estética:

Frente a esse contexto, é apreensível que os idosos tragam em seu cerne o sentimento de não pertencimento psicossocial, por trazerem em seus corpos as marcas que denunciam sua idade, sendo que esse atributo é desvalorizado numa cultura que paradigmaticamente crê que 'o corpo é mais importante do que a roupa' (2011, p. 79).

Essa contextualização gerou certo estranhamento pelo fato de termos um olhar teórico sobre o processo de envelhecimento como campo de possibilidades; resumidamente, pode-se dizer que idealizamos um cenário que destoava daquele que encontramos. Todavia, acreditamos que analisar criticamente o território institucional e os processos de subjetivação que ali se engendravam possibilitou a problematização da experiência do envelhecer em nossa sociedade.

Assim sendo, pensamos que fosse imprescindível primeiramente desconstruirmos idealizações para que pudéssemos intervir frente ao que nos era apresentado; essa ressignificação emergiu como um disparador para que pensássemos em uma proposta que transpusesse a realidade intramuros e que, ao mesmo tempo, engendrasse outros territórios de subjetivação.

Destarte, a intervenção agenciou-se após análise e problematização das afetações produzidas na moldura institucional, de maneira que fomos afetados pelo sentimento de não pertencimento desses velhos ao circuito urbano. Suas rotinas se limitavam à 
circulação pela díade casa - instituição. As conexões possíveis estavam obstruídas pela impossibilidade, osterritórios de subjetivação estavam estanques, produzindo vidas suspensas, nas quais não se vislumbravam planos de novas experimentações.

Partindo-se dessas análises foi que se propôs o projeto de intervenção na instituição de estágio, realizado através de oficinas com passeios pelos circuitos urbanos. $\mathrm{O}$ intento não era simplesmente levar os velhos a saírem do ambiente institucional, mas oferecer um espaço de circulação por outros territórios o encontrar-se em experimentações jamais imaginadas, objetivando-se criar espaços de ressignificação.

Nesse sentido, a proposta do presente artigo é apresentar os caminhos percorridos para a experimentação nos circuitos urbanos bem como um recorte dos afetos que nos atravessaram nessa experimentação, tendo em vista que a intervenção esteve atravessada pelo método cartográfico, que define a relação entre pesquisa-intervençãosaberes em um plano de atravessamentos indissociáveis, conforme definem Passos e Barros: "A diretriz cartográfica se faz por pistas que orientam o percurso da pesquisa sempre considerando os efeitos do processo do pesquisar sobre o objeto da pesquisa, o pesquisador e seus resultados" (2009, p.17).

Diante da acepção de compreendermos o campo de trabalho da Psicologia como uma prática micropolítica, como a define Guattari (1998), sendo essa uma ação que "prolifera a partir de uma multidão de mudanças mutantes: tornar-se mulher, tornar-se criança, tornar-se velho, tornar-se animal, planta, cosmos, tornar-se invisível... - do mesmo modo inventar 'máquinas' (grifos do autor), novas sensibilidades, novas inteligências da existência" (1998, p. 188), objetivou-se dar visibilidade aos múltiplos lugares e formas para a intervenção em Psicologia, dando ênfase ao trabalho do psicólogo em políticas públicas, especificamente em se tratando de assistência social para idosos e suas redes possíveis.

\section{Construindo nosso caminho - projeto de intervenção oficinas com passeios}

O trabalho com o sujeito deve estar contextualizado com a realidade na qual está inserido, porquanto necessariamente se deve propiciar uma intervenção condizente com a demanda da população-alvo. Esse foi o enfoque principal em nossa intervenção, que buscou respeitar a singularidade de cada idoso, como, por exemplo, suas capacidades e o tempo de cada um, para, então, tendo como norteador a demanda do grupo, compor um espaço terapêutico.

Assim, pontua-se que nossa entrada na instituição se deu no ano anterior à intervenção realizada, sublinhando-se que, nessa trajetória inicial, apenas observávamos e interagíamos com os idosos.

Os primeiros contatos foram importantíssimos, no que diz respeito à prática posteriormente desenvolvida, pois possibilitaram o estabelecimento de vínculo com os sujeitos. Em nossos encontros, nós nos sentávamos ao lado de alguns dos idosos, conversávamos ou simplesmente deixávamos o tempo passar, sem pressa. Essa mesma rotina permeou nossos encontros ao longo desse primeiro ano.

No ano posterior, a prática desenvolvida consistia em levantarmos demanda e em elaborarmos um plano interventivo. Ratificase que as fases que constituíram a proposta de intervenção foram balizadas pelo Compêndio de Análise Institucional, de Baremblitt (1996).

Esse autor aborda a confecção de uma proposta de intervenção apresentando um 
Castro, Mattos, Juncken, Monteiro, e Villela (2006) afirmam que o território urbano apresenta-se como um espaço de trocas sociais amplas, núcleo onde transita a mercadoria tanto capital simbólico/cultural quanto capital parcimonioso. roteiro para uma intervenção institucional padrão, que se baseia em etapas a serem seguidas, desde o levantamento da demanda até a operacionalização da intervenção. Assim, Baremblitt afirma que inicialmente problematizamos sobre a diferenciação entre queixa e demanda, já que os sujeitos atendidos podem trazer enraizados em seus discursos queixas (reclamações) que não têm relação com o que demandam.

Dessa forma, foram utilizados como instrumentos observações e entrevistas semiestruturadas, tanto com usuários quanto com funcionários, problematizando principalmente temáticas como: vivências, percepções, expectativas e relacionamento interpessoal. Posteriormente, analisou-se de modo crítico o conteúdo das entrevistas.

O processo de análise dos discursos das entrevistas fundamentou-se em Bravo (2007), que afirma que a realidade institucional gera discursos e práticas que fundamentam o aparelho de controle social, que tem como função institucionalizar o sujeito, entretanto, de forma sutil, na qual o real sentido desse mecanismo é ocultado. Foucault (1999 como citado em Bravo, 2007) corrobora essa afirmativa ao pontuar que as práticas sociais são fontes de saberes que não só se limitam a gerar o inédito, mas também a fazerem surgir formas completamente ímpares de modos de estar no mundo e de sujeitos de conhecimento.

Assim, após análise e discussões supervisionadas, chegamos a uma demanda inicial do sentimento de não pertencer ao território urbano, e principalmente de atrofiamento dos vínculos sociais, uma vez que a rotina dos idosos se limitava a estarem em suas casas ou a frequentarem o centro de convivência. Essa pontuação se refere ao fato de os indivíduos transmitirem em seus discursos a ideia de que seu espaço relacional se resume ao familiar e ao institucional, ou seja, o campo de relação dos idosos é restrito, no sentido de ele se limitar aos locais que usualmente frequentam e pelo fato de os idosos não terem consciência de que esse meio onde estão inseridos representa a parte de um todo.

Nesse sentido, Guattari e Rolnik (2005) contribuem com o tema ao pontuarem que a subjetividade é essencialmente construída no âmbito social, entretanto, é vivenciada pelos sujeitos em suas existências singulares; apesar disso, a maneira de estar no mundo oscila entre dois paralelos: uma relação de alienação e opressão, na qual o sujeito absorve o que o meio social lhe oferece sem problematizar o que lhe é ofertado, ou uma relação de expressão e criação, sendo que, nessa vertente, o indivíduo se apropria de elementos da subjetividade, gerando um processo denominado singularização.

Frente a essa demanda, problematizamos um modo efetivo de intervenção que criasse outros processos de subjetivação. Assim, visualizamos nas oficinas com passeios uma modalidade de atendimento que levaria os idosos a transporem os muros da instituição, possibilitando de certo modo a ampliação da consciência crítica e da capacidade de questionamento acerca de suas possibilidades de experimentação de novos espaços, ou seja, de experenciarem a subjetividade como nômades, e assim, passíveis de se desterritorializarem/reterritorializarem.

Assim, Castro, Mattos, Juncken, Monteiro, e Villela (2006) afirmam que o território urbano apresenta-se como um espaço de trocas sociais amplas, núcleo onde transita a mercadoria tanto capital simbólico/ cultural quanto capital parcimonioso. Nesse sentido, a vida urbana é balizada pela diversidade, pelo diferente que é apresentado e representado em seu espaço público. Magnani (2005) concorda com essa afirmativa quando ressalta que o conceito 
de circuito se refere a uma categoria que descreve o exercício de uma prática ou a disponibilidade de determinado serviço mediante o estabelecimento de emparelhamentos entre espaços que não possuem entre si um relacionamento de proximidade territorial, mas também se refere ao uso do espaço urbano para o exercício da sociabilidade através de encontros.

Perante o que foi anteriormente exposto, percebe-se o circuito urbano como agenciador subjetivo, tão logo que, através da oficina de passeios, objetivou-se propiciar aos idosos a experimentação de lugares diferentes, de modo que o sujeito tivesse a sua capacidade de circulação ampliada, que seus corpos pudessem experenciar novos encontros, possibilitando a reinvenção de si mesmos.

A operacionalização da proposta anteriormente referenciada se deu mediante a apresentação de um projeto de intervenção e do diálogo com a coordenadora do centro de convivência, sendo imprescindível a aprovação de nosso plano de intervenção, já que carecíamos de alguns instrumentos para a sua efetivação.

Dessa forma, avaliamos, com a coordenadora, alguns tópicos como: transporte, número de encontros, tempo de duração e locais visitados. Em se tratando do transporte, citase que a instituição dispõe de uma kombi que comporta nove passageiros, de maneira que a coordenadora disponibilizou o veículo bem como o motorista.

Os tópicos subsequentes foram discutidos tendo como norteador o transporte disponibilizado, uma vez que, devido ao número de passageiros, os idosos seriam divididos por grupos, enfatizando-se que cada grupo seria necessariamente acompanhado por uma cuidadora.
Assim, ressalta-se que, no período em que desenvolvíamos nossas atividades de estágio, a instituição atendia 30 idosos de ambos os sexos, com idades variáveis entre 60 (sessenta) e 80 (oitenta) anos, provenientes de diversos bairros. Pontua-se que, apesar de a instituição estar localizada em um bairro de classe média baixa, seus usuários provêm, em sua maioria, de outros bairros da cidade.

Sublinha-se que o centro de convivência se apresenta como um dispositivo de assistência social, oferecendo proteção básica, de modo que, assim como outros serviços de convivência e de fortalecimento de vínculos para idosos, prioriza o desenvolvimento de atividades que colaborem com o processo de envelhecimento saudável, na promoção da autonomia e da sociabilidade, no fortalecimento dos vínculos familiares e comunitários e na prevenção de risco social. Os serviços supracitados fazem menção ao Decreto no 1.948, de 3 de julho de 1996, que regulamenta a Lei $\mathrm{n} \mathbf{0} 8.842$, de 4 de janeiro de 1994, que dispõe sobre a Política Nacional do Idoso, e dá outras providências (Brasil, 1996).

Com relação ao número de encontros, deve-se observar que não foi definido a priori, pois a participação na oficina não era obrigatória, cabendo aos sujeitos decidirem autonomamente sobre sua participação.

A apresentação da oficina aos idosos se deu posteriormente, ressaltando-se que, na oportunidade, fomos acompanhados pela psicóloga que atua na instituição por quatro horas/semanais; assim, nós os convidamos para um encontro em uma das salas do centro de convivência, onde lhes apresentamos nossa proposta e os questionamos sobre os locais que gostariam que estivessem inclusos em nossos passeios, entretanto, frisamos que os roteiros não eram pré-estabelecidos.

Nesse encontro, os idosos apresentaram- 
se apreensivos, e alguns expuseram que gostaram da oficina, enquanto outros se mantiveram em silêncio; com relação aos locais, não se manifestaram, frisando apenas que gostariam que o asilo fosse um dos lugares. Finalizamos o encontro pontuando que aqueles que desejassem participar da oficina deveriam encaminhar-se à coordenação para se inscreverem. Ressaltou-se que os inscritos seriam subdivididos em grupos de no máximo oito sujeitos, e que, ao final dos encontros, realizar-se-ia um encontro destinado a elaborar a experimentação dos circuitos urbanos.

Assim sendo, ressalta-se que a oficina de passeio se baseou na realização de três encontros, com grupos distintos, não tendo roteiros pré-definidos, de modo que possibilitou o transitar dos idosos por territórios ímpares, como, por exemplo, bosque, lago, biblioteca municipal e aeroporto, dentre outros espaços escolhidos pelos participantes, bem como um encontro de elaboração, realizado com o grupo completo, frisandose que lhes foram entregues fotografias que registraram alguns momentos dos passeios.

Essa forma de intervenção nos permitiu a experimentação, com os idosos, do que os afetava em cada encontro que se materializava. Assim, em cada chegada, eram abertas as possibilidades para um novo encontro, entre indivíduos diversos, com experimentações ímpares, mas que, naquele momento, eram apenas pessoas que se encontravam, trazendo consigo as particularidades constitutivas de suas existências.

\section{"Existirmos, a que será que se destina": experimentações do não planejado}

O encontro com o não planejado foi o tópico principal, pois, em todos os encontros, não éramos apenas estagiários, mas estávamos experienciando cada passeio com nossos corpos representados pela sua totalidade.

Assim, pode-se mencionar que o primeiro grande encontro que tivemos foi com teóricos que balizaram nossa prática. O simples contato com esses pensadores fez emergir a percepção do quanto somos incompletos, de que sempre podemos nos reinventar, e, principalmente, que desprezar algo sem ao menos nos darmos a oportunidade de conhecer é uma atitude um tanto quanto ignorante.

Diante do que expusemos anteriormente, podemos ressaltar que o conhecimento adquirido a partir de revisões bibliográficas é parte imprescindível em qualquer que seja a técnica desempenhada, pois, como bem afirma Guareschi (2007), não existe prática sem teoria.

Em nossa intervenção, ao utilizarmos como método o passeio, percebemos que a experimentação dos espaços originam afetações únicas. Frisa-se que não importa se o lugar era conhecido ou desconhecido, já que o fator significativo era o de realmente nos encontrarmos tanto com aqueles que nos acompanhavam quanto com o lugar representado por sua materialidade.

Assim, pode-se mencionar que a circulação pelo território urbano fez com que nos apreendêssemos como sujeitos da pesquisa, pois nossa prática esteve atravessada pelo método cartográfico, que define a relação entre pesquisa-intervenção-saberes, em um plano de atravessamentos indissociáveis, conforme definem Passos e Barros: "A diretriz cartográfica se faz por pistas que orientam o percurso da pesquisa sempre considerando os efeitos do processo do pesquisar sobre o objeto da pesquisa, o pesquisador e seus resultados" (2009, p.17).

Assim sendo, trazemos resquícios das afetações 
produzidas em nossos encontros com os idosos, foram inúmeros os agenciamentos assistidos, encenados, fazendo com que compreendêssemos que é praticamente impossível em uma pesquisa o pesquisador se intitular neutro.

Pensamos ser importante relatar que experenciamos, em nossa prática, momentos que foram guiados pelo imprevisto, o que demonstrou que, quando nos encontramos com o outro, não podemos prever o que irá acontecer. Dessa forma, a intervenção desenvolvida foi planejada, no entanto, a operacionalização não ocorreu da forma que imaginávamos, fazendo com que a arte do improviso consistente no referencial metodológico fosse prática delineadora para que obtivéssemos o êxito.

Tal pontuação pode ser associada, por exemplo, à questão da mobilidade dos idosos, visto que, devido à idade avançada e à consequente delimitação de movimento, tivemos que adaptar a experimentação de alguns locais com a demanda dos participantes. Contudo, tal acontecido não representou empecilho para que os encontros fossem realizados, mas sim, pontos de imersão de posicionamentos que divergiam dos imaginados, como, por exemplo, o tempo destinado aos encontros em virtude do ritmo motor dos utentes.

\section{Materializando o impensável: experimentações na torre}

Desse modo, apresentaremos o recorte das experimentações de um dos locais que visitamos, que, a nosso ver, transcendeu as nossas ideias sobre a experimentação que os idosos iriam fazer do espaço apresentado. Nesse sentido, pontuamos que o local visitado foi a réplica da torre Eiffel, situada às margens da rodovia PR 323, e ressaltamos que, logo na chegada, os idosos desembarcaram do transporte e em seguida se dirigiram à torre; durante a caminhada, comentavam entre si e conosco: "Que lindo!"; "Achei que ia morrer e não iria conhecer a torre Eiffel"; "Isso é prova de que devemos acreditar que muitas coisas podem acontecer na nossa vida, mesmo que seja por outras pessoas" (sic).

Nesse contexto, salienta-se que o desejo é o que nos move. Sobre essa temática, Guattari e Rolnik (2005, p. 261) contribuem ao pontuar que o conceito de desejo se refere "a todas as formas de vontade de viver, de vontade de criar, de vontade de amar, de vontade de inventar outra sociedade, outra percepção do mundo, outros sistemas de valores".

Dessa forma, apreende-se que o envelhecimento se apresenta como uma época de vida, mas não deve ser enfocado como sinônimo apenas de perdas, porque, assim como outros estágios de desenvolvimento, o envelhecer emerge como campo de possibilidades.

Conforme Goldenberg, em um estudo intitulado Corpo, Envelhecimento e Felicidade na Cultura Brasileira, a experimentação do envelhecimento pode receber modos peculiares de significado pelos idosos, sendo comum encontrarem-se sujeitos que associam o envelhecer ao período da felicidade, uma vez que esse é um período que não traz a necessidade de engendrar projetos, ou seja, alguns indivíduos não permitem que os outros os tornem invisíveis. Muitos nunca serão velhos, mas homens e mulheres que envelhecem dando continuidade aos seus projetos existenciais, que continuam cantando, dançando, criando, buscando a felicidade e o prazer, transgredindo as normas e os tabus existentes. "Mais livres e visíveis do que nunca, são aqueles que podem ser chamados de ageless, ou 'os sem idade' (grifos do autor)" (Goldenberg, 2011, p.83).

Detalhada tal temática, ressalta-se que, 
frente à experimentação da torre, alguns idosos, tomados pelo desejo e não sendo impedidos em nenhum momento, subiram as escadas que levam ao topo da réplica da torre Eiffel - a monitora que acompanhava o grupo subiu até certa altura - ; enquanto isso, o restante dos idosos permaneceu em solo juntamente ao motorista do transporte e a uma das estagiárias.

Assim, percebe-se que, mesmo o corpo estando sob o domínio do discurso, capturado através do desejo, ele desprendese dessas amarras, transformando-se em um corpo desejante. Foucault (1979) ressalta que o corpo está sob o domínio dos discursos dominantes que, através de seus mecanismos, o controlam de forma sutil, entretanto, o corpo é como um mosaico que é constituído a partir de inúmeras partes de tamanhos diversos, o que faz com que ele seja incompreensível.

Com tal afirmativa, objetiva-se ressaltar que os processos de agenciamento subjetivo emergem em qualquer que seja o campo relacional, de maneira que o devir somente será extinto quando o sujeito está em processo de assujeitamento, quando a máquina desejante está capturada pelos discursos das linhas molares.

Segundo Foucault (1994 como citado em Sampaio, 2011, p. 125), os processos de agenciamento subjetivo são balizados por movimentos de destruição e de construção. Isso quer dizer que desconstruímos o que somos e criamos algo inédito, em um processo de total invenção de si mesmo.

Chegando ao topo da torre Eiffel, os idosos fizeram comentários: "Que vista linda!"; "Será que isso não cai?"; "Eu nunca imaginei que na vida eu faria isto" (sic). As falas descritas há pouco materializavam a experimentação do novo no corpo envelhecido, em um processo de desterritorialização.
Tais reflexões são partilhadas por Guattari (1998) quando este afirma que o espaço é percebido de acordo com as normas e os rituais sociais dominantes, sendo entendido como local de agenciamentos coletivos ou individuais, territorializados ou desterritorializados, maquínicos ou construídos. Entretanto, podem ser percebidos processos de singularização que são caracterizados pela experiência de um grupo de se fazer, em outras palavras, de captar elementos da situação, que construam seus próprios referenciais práticos e teóricos, sem que haja uma relação de dependência.

A partir do momento em que o grupo adquire liberdade de vivenciar seus processos, ele se capacita a entender o que se passa em torno dele, sendo que essa capacidade vai permitirIhe criar e preservar a autonomia (Guattari \& Rolnik, 2005).

Desse modo, percebe-se, tendo como respaldo os relatos dos idosos, que realmente o circuito é um agenciador subjetivo, posto que os espaços que nos circundam são habitados por outros humanos como nós, mas que são singulares em relação aos seus processos subjetivos.

Assim, pontua-se que a visita à torre foi a que mais repercutiu, pois, na subida, notou-se que alguns dos idosos transcenderam suas limitações ao serem movidos pelo desejo de experimentar a sensação de estar no topo da réplica.

Sublinha-se ainda que, em alguns discursos, é perceptível que muitos deles nem imaginavam que conheceriam aquele local, nem tampouco tinham ideia de como era a torre e muito menos de que iriam subir até o último degrau.

Uma das idosas usava bengala, e, na experimentação de chegar ao topo da torre, relata que até havia se esquecido da limitação 
das pernas, de modo que, ante os relatos, percebe-se o grande entusiasmo que nossa proposta interventiva provocou em suas vidas, ou seja, nossos encontros foram o palco de múltiplas afetações, e principalmente, levaram-nos a perceber o quanto o humano é capaz de experimentar o impensado e principalmente de maravilhar-se.

Finaliza-se citando que, mediante conversas com funcionários que não participaram de nossa oficina, mas que presenciaram a mudança dos usuários em momentos antecedentes ou subsequentes aos passeios, percebeu-se que o objetivo de nossa proposta havia sido atingido.

Fundamenta-se tal afirmativa nas palavras da professora de yoga: "Durante os dias do circuito, entre o primeiro e o terceiro, não se experimentou tamanho entusiasmo na instituição". O motorista, por sua vez, argumentou: "No domingo anterior, depois dos circuitos, levei a família: mulher, filhos, irmão, mãe, para fazerem o mesmo circuito, não podia imaginar que eles iriam gostar tanto".

A proposta afetou não só os corpos envelhecidos do local do estágio mas também todos os que pertencem a essas vidas, que foram contaminados pela experimentação dos circuitos urbanos, e, por esse motivo, percebemos que realmente afetamos e somos afetados pelo meio que nos circunda, de forma que retomamos o conceito de desejo apresentado por Guattari e Rolnik (2005), que nos mostra de forma bem clara o quanto somos seres de desejos, de produção desejante, sendo essa maquinaria desejante produtora de caminhos a serem caminhados e experimentados em afetações, sendo possível e realizável um corpo cansado e envelhecido vislumbre e se lance para o impensado.

Aquilo que nos é apresentado no mundo já carrega em si significados que objetivam nos normatizar e, sobretudo, nos levar a concluir que sempre foi daquele jeito e que não é passível a mudança, ou seja, desde pequenos, somos coisificados e institucionalizados, pois temos que seguir regras, obedecer a horários, resumindo, ser a pessoa que querem que sejamos.

Assim sendo, pode-se pontuar que a máquina de produção de subjetividade atua no indivíduo desde sua infância quando este é inserido no universo dos discursos dominantes, ao passo que, a partir desses discursos, criamse modelos aos quais ele deve integrar-se, sendo que a tendência contemporânea é igualar tudo por meio da categorização unificadora e reducionista (exemplo: o trabalho, a cultura, a informação), tornando o processo de singularização inviável, mediante o fato de o potencial criativo do indivíduo tanto no campo social quanto tecnológico ser esmagado desde sua inserção no âmbito do que diz a classe dominante (Guattari \& Rolnik, 2005).

Dessa forma, a instituição na qual desenvolvemos nossa prática de estágio não poderia fugir da configuração de palco normativo, no qual os idosos que frequentam o ambiente são como atores que encenam uma peça norteada por scripts.

Frente a essa compreensão, é como se a vida institucionalizada fosse balizada pela imposição sutil de papéis sociais. Dessa maneira, os papéis são distribuídos conforme o poder que cada indivíduo exerce sobre o outro, e, conforme tal entendimento, cada um tem sua função bem delineada, em que são divididos entre cuidadores e cuidados.

Através dessas articulações, o idoso é visto através da óptica da dependência, e, por isso, destituído de autonomia e principalmente de possibilidades de novas experimentações; grosso modo, é como se 
o envelhecimento impossibilitasse novos agenciamentos subjetivos. Em consequência, o idoso passa a ser tratado como criança, não no sentido de poder transcender o dado, mas no sentido da dependência e, especialmente, da necessidade do cuidado.

O idoso, portanto, passa a se ver através das objetivações que lhe atribuem, e passa a existir como coadjuvante da própria história, ou seja, reina em sua vida uma total falta de autonomia, que pode ser facilmente percebida nos seus discursos, demonstrando que os idosos parecem ser passivos, atuando apenas como esponjas que apenas absorvem as significações que lhe são apresentadas como intrínsecas.

Diante de tal posicionamento, parecem dizer que acabaram as suas possibilidades, que, no momento atual, não podem transcender o estabelecido, apenas aceitar passivamente sua nova condição de dependência e, sobretudo, perceberem-se a partir de seus estigmas e aceitarem sem questionar a segregação que lhes é instituída.
Através da desmistificação da constituição subjetiva como processo natural, o indivíduo nota que pode estar sempre mais além daquilo que está vivendo. Nessa perspectiva, o encontro com a diferença nos faz ao mesmo tempo mais humanos e conscientes, levando-nos a pensar na existência a partir do dado irreproduzível das experimentações constitutivas do próprio existir; salienta-se que nossa idade cronológica não pode ser considerada um marco que delimita nossas impossibilidades.

Conclui-se que nunca se é tão velho que não se possa experenciar o que é ser humano. Quando se fala em ser humano, trazse a humanidade representada pela sua característica ímpar em relação às demais coisas: a sua capacidade de se metamorfosear, ou seja, de mudar, de transcender o dado e de experenciar como sujeito o ato dos povos nômades: existir em um constante movimento de se desterritorializar e se reterritorializar, enfim, viver a humanidade naquilo que ela tem de singular: a possibilidade de, a cada novo dia, se reinventar. 


\title{
Méri Vanessa Elias
}

Psicóloga formada pela Universidade Paranaense, Formosa do Oeste - PR - Brasil.

E-mail: meri_vanessa_1989@hotmail.com

\section{Sidineia Aparecida Pizzeti}

Psicóloga formada pela Universidade Paranaense, Terra Roxa - PR - Brasil.

E-mail: sidineia_pizzeti@hotmail.com

\section{Danielle Jardim Barreto}

Mestre e doutoranda em Psicologia pela Universidade Estadual Paulista Júlio de Mesquita Filho e docente e coordenadora do curso de Psicologia da Universidade Paranaense, Umuarama - PR - Brasil.

E-mail: danibarreto@unipar.br

\section{Endereço para envio de correspondência:}

Rua Maria Elizabeth Parrales, 102, Centro. CEP: 85830-000. Formosa do Oeste, PR.

\author{
Recebido 15/06/2012, 1a Reformulação 01/02/2013, Aprovado 11/04/2013
}

Baremblitt, G. F. (1996). Compêndio de análise institucional e outras correntes: teoria e prática. Rio de Janeiro: Rosas dos Tempos.

Brasil. (1996). Decreto n.o 1.948, de 3 de junho de 1996. Regulamenta a Lei n. 9842 , de 4 de janeiro de 1994 , que dispõe sobre a Política Nacional do Idoso e dá outras providências. LEX: Coletânea de Legislação e Jurisprudência, 60,1657-61.

Bravo, A. O. (2007, ago.). As prisões da loucura, a loucura das prisões. Psicol. Soc., 19(2), 34-41. Recuperado em 17 abr., 2012, de http://www.scielo.br/pdf/psoc/v19n2/a05v19n2.pdf

Castro, L. R., Mattos, A. R., Juncken, E. T., Monteiro, R. A. de P., \& Villela, H. A. M. (2006, ago.). A construção da diferença: jovens na cidade e suas relações com o outro. Psicol. Estud., 11(2), 437-447. Recuperado em 17 abr., 2012, de http:// www.scielo.br/pdf/pe/v11n2/v11n2a22.pdf

Foucault, M. (2004). Microfísica do poder. São Paulo: Graal.

Guareschi, P. A. (2007). Relações comunitárias - relações de dominação. In R. H. F. Campos (Org.), Psicologia social comunitária: da solidariedade à autonomia (pp. 81-99). Petrópolis, RJ: Vozes.

Guattari, F. (1998). O inconsciente maquínico: ensaios de esquizoanálise. Campinas, SP: Papirus.
Guattari, F., \& Rolnik, S. (2005). Micropolítica: cartografias do desejo. Petrópolis, RJ: Vozes.

Goldenberg, M. (2011). Corpo, envelhecimento e felicidade na cultura brasileira. Rev. Contemporânea, 9(18), 77-85.

Magnani, C. G. J. (2005). Os circuitos dos jovens urbanos. Tempo Social - Revista de Sociologia da USP, 17(2), 173-205.

Maia, G. F. da, Castro, G. D., \& Jordão, A. B. (2010, março). Ampliando a clínica com idosos institucionalizados. Rev. MalEstar Subj., 10(1), 193-210 Recuperado em 12 jan., 2013, do PePSIC http://pepsic.bvsalud.org/pdf/malestar/v10n1/ v10n1a09.pdf

Morais, O. N. P. de. (2009). Grupos de idosos: atuação da psicogerontologia no enfoque preventivo. Psicologia: Ciência e Profissão, 29(4), 846-855. Recuperado de 12 jan., 2013, http://www.scielo.br/scielo.

Passos, E., \& Barros, R. B. de. (2009). A cartografia como método de pesquisa-intervenção. In E. Passos, V. Kastrup \& L. da Escóssia. (Org.), Pistas do método da cartografia: pesquisaintervenção e produção da subjetividade (pp. 17-31). Porto Alegre: Sulina.

Sampaio, S. S. (2011, dez.). A liberdade como condição das relações de poder em Michel Foucault. Rev. Katálysis, 14(2), 222-229. Recuperado em 12 jan., 2013, de http://www.scielo. $\mathrm{br} / \mathrm{pdf} / \mathrm{rk} / \mathrm{v} 14 \mathrm{n} 2 / 09 . \mathrm{pdf}$ 